\title{
MINI-GASTRIC BYPASS: DESCRIPTION OF THE TECHNIQUE AND PRELIMINARY RESULTS
}

\author{
Mini-bypass gástrico: Descrição da técnica e resultados preliminares \\ Elinton Adami CHAIM ${ }^{1}$, Almino Cardoso RAMOS', Everton CAZZO'
}

From the 'Departamento de Cirurgia, Faculdade de Ciências Médicas, Universidade Estadual de Campinas (UNICAMP), Campinas, SP e Instituto Gastro-Obeso Center ('Department of Surgery, Faculty of Medical Sciences, State University of Campinas UNICAMP, Campinas, and 2Instituto GastroObeso Center, São Paulo), SP, Brazil

HEADINGS - Bariatric surgery. Gastric bypass. Obesity. Bile reflux. Gastroenterostomy.
ABSTRACT - Background: In recent years, a surgical technique known as single-anastomosis gastric bypass or mini-gastric bypass has been developed. Its frequency of performance has increased considerably in the current decade. Aim: To describe the mini-gastric bypass technique, its implementation and preliminary results in a university hospital. Methods: This is an ongoing prospective trial to evaluate the long-term effects of mini-gastric bypass. The main features of the operation were: a gastric pouch with about $15-18 \mathrm{~cm}(50-150 \mathrm{ml})$ with a gastroenteric anastomosis in the pre-colic isoperistaltic loop $200 \mathrm{~cm}$ from the duodenojejunal angle (biliopancreatic loop). Results: Seventeen individuals have undergone surgery. No procedure needed to be converted to open approach. The overall 30-day morbidity was $5.9 \%$ (one individual had intestinal obstruction caused by adhesions). There was no mortality. Conclusion: Mini-gastric bypass is a feasible and safe bariatric surgical procedure.

\section{Correspondence: \\ Everton Cazzo \\ E-mail: notrevezzo@yahoo.com.br; \\ evertoncazzo@yahoo.com.br}

Financial source: $\quad$ Scitech $^{\circledast}$ provided disposable trocars, staplers and cartridges.. Conflict of interest: Almino Cardoso Ramos é speaker da Ethicon, WL Gore, MSD e Scitech

Received for publication: 11/05/2017 Accepted for publication: 28/09/2017

DESCRITORES - Cirurgia bariátrica. Derivação gástrica. Obesidade. Refluxo biliar. Gastroenterostomia.
RESUMO - Racional: Nos últimos anos foi desenvolvida técnica cirúrgica conhecida como derivação gástrica com anastomose única ou mini-bypass gástrico. A frequência com que este procedimento vem sendo realizado aumentou consideravelmente na última década. Objetivo: Descrever a técnica do procedimento, sua implementação e resultados preliminares em um hospital universitário. Métodos: Estudo prospectivo em andamento para avaliar os efeitos em longo prazo do mini-bypass gástrico. As principais características do mini-bypass gástrico laparoscópico foram: uma bolsa gástrica com cerca de 15-18 cm (50-150 ml) com anastomose gastroentérica em alça isoperistáltica pré-cólica a $200 \mathrm{~cm}$ do ângulo duodenojejunal (alça biliopancreática). Resultados: Foram operados 17 pacientes. Nenhum procedimento necessitou conversão para laparotomia. A morbidade global em 30 dias foi de 5,9\% (um caso de obstrução por brida). Não houve mortalidade. Conclusão: 0 mini-bypass gástrico é procedimento cirúrgico bariátrico factível e seguro.

\section{INTRODUCTION}

$\mathrm{T}$ he prevalences of obesity and overweight have reached epidemic proportions in the last decades, with estimates by the World Health Organization (WHO) pointing that about 2 billion people are at least overweight worldwide ${ }^{9,29}$.

Bariatric surgery has been performed with increasing frequency around the world over the last decades, especially because of the extremely superior results in relation to long-term sustained weight loss and resolution of comorbidities than those observed with non-surgical therapies ${ }^{4,57,7,27}$. The overall impact of bariatric surgery has been demonstrated, with reductions of $40 \%$ on the mortality for any cause, $56 \%$ for coronary disease, $92 \%$ for complications of diabetes, and $60 \%$ for any malignant neoplasia ${ }^{1}$.

After almost 50 years of evolution from the initial descriptions proposed by Mason and Ito ${ }^{16}$, the laparoscopic Roux-en-Y gastric bypass became one of the surgical procedures of reference for the treatment of morbid obesity. However, despite its recognized efficiency and safety, this procedure presents considerable technical difficulty, even for experienced surgeons with appropriate training ${ }^{14}$.

In recent years, a surgical technique known as single-anastomosis gastric bypass (SAGB) or mini-gastric bypass (MGB) has been developed; its frequency of performance has increased considerably in the current decade. ${ }^{26}$ Initially described by Rutledge ${ }^{26}$, this procedure proposes a simplification of Roux-en-Y bypass by performing a single anastomosis, with a significant reduction of technical complexity, shorter operative time and a potential reduction in morbidity and mortality. Several studies have demonstrated the benefits provided by this procedure, including excess weight loss and resolution of comorbidities equivalent or even higher than those observed after the Roux-en-Y gastric bypass ${ }^{3,6,610,12,13,17,19,21,23,25,28}$.

This study aims to describe the mini-gastric bypass technique and its implementation and preliminary results in a university hospital. 
METHODS

This study was designed as a detailed description of a surgical technique and the preliminary outcomes obtained in the first operated cases. It is part of a larger ongoing trial evaluating the long-term effects of MGB which underwent evaluation and was approved by the local Ethics Research Board under the reference Unicamp/1.957.057. Bariatric surgery was warranted based on the National Institutes of Health consensus statement ${ }^{20}$ and Brazilian Department of Health recommendations ${ }^{18}$. All individuals who took part in the study provided informed consent. All the procedures were performed by the same surgical team. The outcomes evaluated in the current study were: surgical time, estimated intra-operative bleeding, 30-day morbidity and mortality, hospital stay, and number of cartridges utilized.

\section{Positioning of the patient and the surgical team}

The operation is performed with the patient in the supine position with legs open and with 45 degrees inclined position. The attachment of the patient to the surgical table is made by placing two belts (on the abdominal area and below the level of the thighs, respectively). The surgeon stands between the legs, with the $1^{\text {st }}$ assistant, who handles the camera and the auxiliary clamp, and the scrub on the right. Urinary bladder catheterization is not used. Antibiotic prophylaxis were routinely administered. The prevention of thrombotic events is made with use of graduated compression stockings and intermittent pneumatic boots. A disposable orogastric tube (Fouchet $32-\mathrm{Fr}$ ) is routinely placed.

\section{Pneumoperitonium e placement of the trocars}

The pneumoperitoneum is performed by means of a direct puncture with a Veress needle in the left upper quadrant, near the costal margin at the level of the midclavicular line (Palmer's point). The initial pressure is set at $15 \mathrm{mmHg}$, and maintained till the expected pressure (about $15 \mathrm{mmHg}$ ) is reached. The surgery initiates by the placement of the $10 \mathrm{~mm}$ permanent trocars for introduction of 30 degrees optics/camera placed at the mesogastrium between $12-15 \mathrm{~cm}$ below the xiphoid process and $3 \mathrm{~cm}$ to the left of the midline, considered as number 1 trocar. The trocar number 2 , of $5 \mathrm{~mm}$, is placed near the xiphoid process for the use of liver retractor which is usually a stick/probe held by the $2^{\text {nd }}$ assistant. The number 3, disposable of $12 \mathrm{~mm}$, is used by the surgeon's left hand, placed on the right side of the patient in an intermediate position between the previous two, $3-5 \mathrm{~cm}$ lateral to the midline. The number 4, also permanent of $5 \mathrm{~mm}$, is placed along the left costal margin in the anterior axillary line to the $1^{\text {st }}$ assistant. The last trocar, number 5, disposable of $12 \mathrm{~mm}$, is placed adjacent to the left costal margin in the hemi-clavicular line to surgeon's right hand manipulation. The pneumoperitoneum is maintained by trocar number 5 . Figure 1 presents the trocars' placement ${ }^{22}$.

\section{Surgical Technique}

Theoperation begins with the dissection of the esophagogastric angle and the opening of the left gastrophrenic ligament with a harmonic scalpel, so as to expose the lateral aspect of the left diaphragmatic crus. Then, the ressection of the fat pad of the esophagogastric junction (Belsey's fat) is performed. Then, the surgeon proceeds the ligation of the distal lesser sac, next to the insertion of the Latarjet nerve, using a harmonic scalpel until the exposure of the posterior gastric wall. The gastric pouch must be lengthy and narrow, measuring around $15-18 \mathrm{~cm}$, with a $50-150 \mathrm{ml}$ reservoir capacity. The pouch is created using 01 unit of $45 \mathrm{~mm}$ blue cartridges to perform the horizontal section and 02 to 03 units to perform the vertical section. The stapling lines of the pouch and excluded stomach are then reinforced with a 3-0 polydioxanone continuous suture. The Treitz ligament is then identified and the small bowel is counted until $200 \mathrm{~cm}$ from the Treitz angle, determining the exclusion of part of the stomach, duodenum, and proximal jejunum from the food pathway. This segment is then attached to the pouch and a vertical or slightly oblique omega-loop, isoperistaltic, antecolic, and side-to-side $25 \mathrm{~mm}$-gastrojejunostomy is performed using a $45 \mathrm{~mm}$ white cartridge; the orifice for the cartridge insertion is closed by means of a continuous suture with 3-0 polydioxanone reinforced with separate stitches of 3-0 polyester. The Petersen's defect is closed by means of a continuous suture with 3.0 silk $^{9}$. The placement of a silicone ring around the gastric pouch is randomly opted following the study protocol for evalution of the effects of the ring. The randomization is performed by means of an electronic device and the individuals are notified of the result of the randomization process prior to the surgery. Among the individuals which have a $6.5-\mathrm{cm}$ silicone ring placed, it is attached to the pouch with 3-0 polypropylene stitches. Figure 2 presents a schematic representation of the surgical technique. ${ }^{24}$

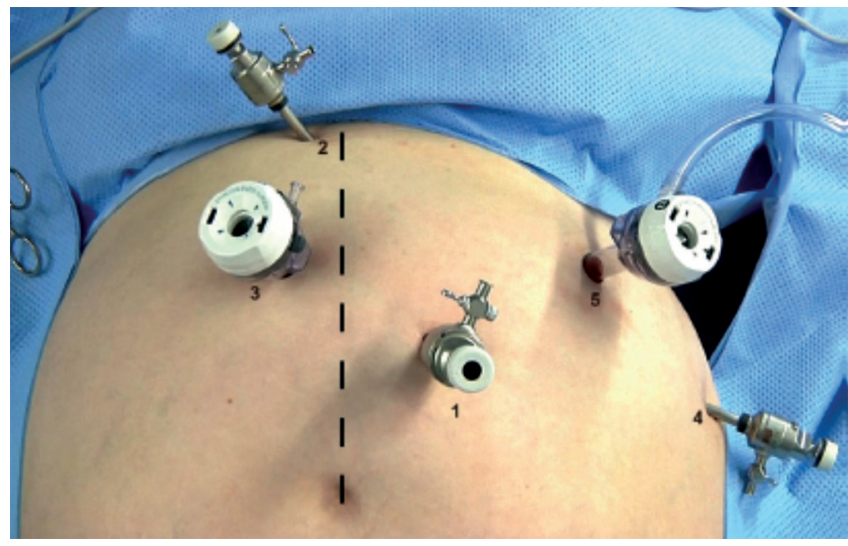

FIGURE1 - Placement of the trocars (Adapted from Ramos et al..$^{22}$ )

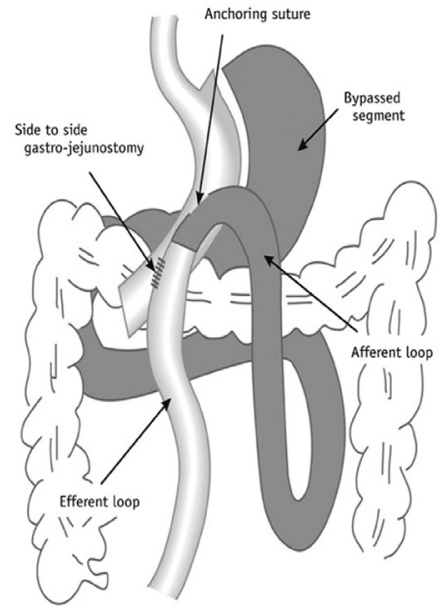

FIGURE 2 - Schematic representation of the mini-gastric bypass (Adapted from Park et al. ${ }^{24}$ )

\section{Postoperative Protocol}

All individuals which underwent surgery remained in a fasting state for 48 hours. Then, an oral methylene blue challenge and a contrast upper radiograph series are performed. Whether there is no evidence of leaks, oral diet is initiated and the individuals are discharged on postoperative day $03^{9}$.

RESULTS

Until the submission of this study, 17 individuals have undergone surgery. No procedure needed to be converted to the open approach. The overall 30-day morbidity was 5.9\% (one individual who presented with intestinal obstruction caused by adhesions). There was no mortality. The detailed results are presented in Table 1. 
TABLE 1 - Characteristics of the study group and early postoperative outcomes $(n=17)$

\begin{tabular}{l|c} 
N & 17 \\
\hline Gender & M: $4(23.5 \%) ; \mathrm{F}: 13(76.5 \%)$ \\
\hline Body mass index $(\mathrm{kg} / \mathrm{m} 2)$ & $36.5(35-50.1)$ \\
\hline Approach & Laparoscopic: $17(100 \%)$ \\
\hline Conversions to Open Approach & 0 \\
\hline Operative time (minutes) & $64.3(45-120)$ \\
\hline Estimated bleeding $(\mathrm{mL})$ & $14.7(0-100)$ \\
\hline Hospital stay (days) & $3.1(3-5)$ \\
\hline Stapler cartridges per procedure & $4.3(4-5)$ \\
\hline Readmissions & $1(5.9 \%)-$ Intestinal obstruction
\end{tabular}

\section{DISCUSSION}

The major concern regarding the MGB technique is the potential risk of gastric and esophageal cancer due to the possibility of biliary reflux to the gastric pouch and gastroesophageal junction. However, a number of traits were added to this surgical technique since its inception, especially to minimize these risks ${ }^{25,26}$. The Mason loop gastric bypass and the Billroth II partial gastrectomy are the two procedures which at first sight seem to be very look alike the $\mathrm{MGB}^{15}$. Albeit based on the same premises, MGB presents substantial advances from the failures of these procedures. Firstly, the pouch, which is lengthier and narrower than that of the classic gastric bypass, is designed to understate the reflux of enteric secretion through the anastomosis. Secondly, the anastomosis itself, which is vertical or slightly oblique in the posterior wall of the pouch, favors the gastric emptying and potentially avoids significant reflux. Both Mason loop bypass and Billroth II gastrectomy were based on large horizontal pouches, which did not support the gastric emptying and also could facilitate the occurrence of gastric stasis, thus favoring the biliary reflux. Furthermore, the distance from the Treitz angle, composing a long biliopancreatic limb (around $200 \mathrm{~cm}$ ) permits the resorption of large amounts of the biliary secretion; thus, the enteric juice that arrives at the anastomosis site is not so concentrated as the one which usually arrived at the Billroth II gastrectomy design ${ }^{15,25,26}$.

Besides these design issues, there are also other issues raised in relation to the carcinogenesis of biliary reflux. Based on in vitro and animal studies, it has been suggested that the reconstruction with a loop configuration in patients undergoing gastric bypass could increase the risk of gastric and esophageal cancers. ${ }^{2,11}$ However, although in the 1960 s and 1970 s thousands of Mason loop gastric bypasses have been performed, there was only a single case report of cancer in the gastric pouch following this surgery2; accordingly, even after tens of thousands of MGBs performed since 1997, there has been only one gastric cancer reported in a MGB patient - and it was in the bypassed stomach and not in the pouch ${ }^{30}$. Since the the overall annual incidence of both these cancers is estimated to be one case per 7,000-10,000, this historical data is significant ${ }^{11,15}$.

The current study revealed significant results in regards to early outcomes; MGB led to both early morbidity and mortality comparable to those observed after RYGB. Furthermore, due to its simplified design and the necessity to perform a single anastomosis, it is simpler and potentially more cost-effective, since less stapler cartridges are necessary.

The major limitations of this study are the small sample of individuals who underwent surgery and the short postoperative follow-up time; both these factors do no permit a thorough evaluation of the long-term risk-effectivity ratio and inferences on the late outcomes of this procedure. Nonetheless, since the main objective of this study was to show the feasibility of the procedure, further research and long-term follow-up are needed to provide more evidence in regards to its long-term outcomes.
MGB is a feasible and safe bariatric surgical procedure.

REFERENCES

1. Adams TD, Gress RE, Smith SC, et al. Long-term mortality after gastric bypass surgery. N Engl J Med 2007;357(8):753-61.

2. Babor R, Booth M. Adenocarcinoma of the gastric pouch 26 years after loop gastric bypass. Obes Surg. 2006;16:935-8.

3. Bruzzi M, Rau C, Voron T, et al. Single anastomosis or mini-gastric bypass: long-term results and quality of life after a 5-year follow-up. Surg Obes Relat Dis 2014 Sep 16. pii: S1550-7289(14)00341-4.

4. Buchwald $H$, Avidor $Y$, Braunwald $E$, et al. Bariatric surgery: a systematic review and meta-analysis. JAMA 2004;292(14):1724-37.

5. Buchwald $\mathrm{H}$. Evolution of operative procedures for the management of morbid obesity. ObesSurg 2002;12:705-717. 14

6. Carbajo MA, Fong-Hirales A, Luque-de-León $E$, et al. Weight loss and improvementoflipid profilesinmorbidlyobesepatientsafterlaparoscopic one-anastomosis gastric bypass: 2-year follow-up. Surg Endosc. 2016 Jun 17. [Epub ahead of print]

7. Cazzo E, Gestic MA, Utrini MP, et al. GLP-2: a poorly understood mediator enrolled invarious bariatric/metabolicsurgery-related pathophysiologic mechanisms. Arq Bras Cir Dig. 2016;29(4):272-275.

8. Cazzo E, Gestic MA, Utrini MP, et al. Correlation between pre and postoperative levels of GLP-1/GLP-2 and weight loss after Roux-en-Y gastric bypass: a prospective study. Arq Bras Cir Dig. 2016;29(4):257-259.

9. Chaim EA, Pareja JC, Gestic MA, et al. Preoperative multidisciplinary program for bariatric surgery: a proposal for the Brazilian Public Health System. Arq Gastroenterol. 2017;54(1):70-74.

10.ChevallierJM,Arman GA, GuenziM, etal.Onethousandsingleanastomosis (omega loop) gastric bypasses to treat morbid obesity in a 7-year period: outcomes show few complications and good efficacy. Obes Surg. 2015 Jun;25(6):951-8.

11. Collins BJ, MiyashitaT, SchweitzerM, etal.Gastric bypass:Why Roux-en-Y. A review of experimental data? Arch Surg. 2007;142:1000-4

12. Lee WJ, Lin YH. Single-anastomosis gastric bypass (SAGB): appraisal of clinical evidence. Obes Surg. 2014 Oct;24(10):1749-56.

13. Lee WJ, Ser KH, Lee YC et al.: Laparoscopic Roux-en-Y vs. Minigastric bypass for the treatment of morbid obesity: A 10-year experience. ObesSurg 2012;22:1827-1834.

14. Madan AK, Harper JL, Tichansky DS. Techniques of laparoscopic gastric bypass:on-linesurvey of AmericanSocietyforBariatricSurgery practicing surgeons. SurgObesRelat Dis 2008;4:166-173.

15. Mahawar KK, Kumar P, Carr WR, et al. Current status of mini-gastric bypass. J Minim Access Surg. 2016 Oct-Dec;12(4):305-10.

16.MasonEE, ItoC.Gastricbypassinobesity.SurgClinNorthAm1967;47(6):1345-51.

17. Milone $M$, Lupoli R, Maietta $P$, et al. Lipid profile changes in patients undergoing bariatric surgery: A comparative study between sleeve gastrectomy and mini- gastric bypass. Int J Surg. 2015 7;14C:28-32.

18. Ministério da Saúde do Brasil. Portaria n. 424, 19 de março de 2013.

19. Musella M, Susa A, Greco F et al.: The laparoscopic mini-gastric bypass: The Italian experience: Outcomes from 974 consecutive cases in a multicenter review. SurgEndosc 2014;28:156-163.

20. National Institutes of Health. Gastrointestinal surgery for severe obesity. Consensus Statement 1991;9(1):1-20.

21. Noun R, Skaff J, Riachi E et al.: One thousand consecutive mini-gastric bypass: short- and long-term outcome. ObesSurg 2012;22:697-703.

22. Park HJ, Hong SS, Hwang J, Hur KY. Mini-gastric bypass to control morbid obesity and diabetes mellitus: what radiologists need to know. Korean J Radiol. 2015 Mar-Apr;16(2):325-33.

23. Piazza L, Ferrara F, Leanza $S$, et al. Laparoscopic mini-gastric bypass: short-term single-institute experience. Updates Surg 2011;63(4):239-42.

24. Ramos AC, Silva AC, Ramos MG, et al. Simplified gastric bypass: 13 years of experience and 12,000 patients operated. Arq Bras Cir Dig. 2014;27 Suppl 1:2-8.

25. Rutledge R, Walsh TR. Continued excellent results with the mini-gastric bypass: six-year study in 2,410 patients. ObesSurg 2005;15(9):1304-8.

26. Rutledge $R$. The mini-gastric bypass: experience with the first 1,274 cases. Obes Surg 2001;11(3):276-80.

27.SjöholmK, SjöströmE, CarlssonLM, PeltonenM.WeightChange-Adjusted Effects of Gastric Bypass Surgery on Glucose Metabolism: 2- and 10Year Results From the Swedish Obese Subjects (SOS) Study. Diabetes Care 2016;39(4):625-31.

28. Victorzon M. Single-anastomosis gastric bypass: better, faster, and safer? Scand J Surg. 2015 Mar;104(1):48-53.

29. WHO. Obesity and overweight Updated June 2016. Em: <http://www. who.int/mediacentre/factsheets/fs311/en/>.Accessed onAugust, 2017.

30.WuCC, LeeWJ,SerKH, etal.Gastriccanceraftermini-gastricbypasssurgery: A case report and literature review. Asian J Endosc Surg. 2013;6:303-6. 